\title{
In situ studies on radiation tolerance of nanotwinned $\mathrm{Cu}$
}

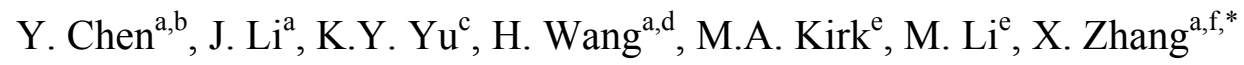 \\ ${ }^{a}$ Department of Materials Science and Engine ering, Texas A\&M Universi ty, College Station, \\ TX 77843 USA \\ ${ }^{\mathrm{b}}$ MPA-CINT, Los Alamos National Laboratory, Los Alamos, NM 87545, USA \\ c Department of Materials Science and Engin eering, China University of Petroleum -Beijing, \\ Beijing, 102246 China \\ ${ }^{\mathrm{d}}$ Department of Electrical and Computer Engi neering, Texas A\&M University, College Station, \\ TX 77843 USA \\ ${ }^{\mathrm{e}}$ Nuclear Engineering Division, Argonne National Laboratory, Argonne, Illinois 60439, USA. \\ ${ }^{\mathrm{f}}$ Department of Mechanical Engineering, Te xas A\&M University, College Station, TX 77843 \\ USA \\ * Corresponding author: X. Zhang, zhangx@tamu.edu, Tel: (979) 845-2143
}

\begin{abstract}
We investigate the radiation response of nanotwinned $\mathrm{Cu}$ by using in situ $\mathrm{Kr}$ ion irradiation technique inside a transmission electron $\mathrm{m}$ icroscope. In com parison with coarse grained $\mathrm{Cu}$, nanotwinned $\mathrm{Cu}$ exhibits smaller defect size and lower defect density. In situ studies also show that twin boundaries effectively remove a large num ber of defect clusters. The life time of defect clusters in nano twinned $\mathrm{Cu}$ is very different $\mathrm{fr}$ om that in its co arse grained counterpart. This study provides further evidence on twin-boundary enabled radiation tolerance in nanotwinned metals.
\end{abstract}

Keywords: nanotwins, radiation damage, in situ, defect kinetics 


\section{Introduction}

Irradiation of metallic materials by neutrons or heavy ions results in a la rge number of vacancy and interstitial clusters. Typical defect clusters include stacking fault tetrahedra (SFTs), Frank loops, dislocation loops a nd voids [1-7], which tend to grow further under continous radiation process, causing severe d egradation of mechanical properties in irrd iated metallic materials [8-10]. To alleviate radiation dam age in these materials, various types of defect sinks have been studied, including grain boundaries, phase boundaries and twin boundaries. Grain boundary is one of the prim ary defect sinks that can effectively reduce radiation induced defect density [11-16] and curtail void swelling [17-24]. Phase boundaries in ferritic/ martensitic steels [25-27], oxide dispersion strengthened (ODS) all oys[28, 29] and nanolayered structures [30-34] have also attracted increasing attention as these boundaries can be effective defect sinks.

Nanotwinned (nt) $m$ etals have also shown enhanced radiation tolerance due to the existence of high-density twin boundaries (TBs) [35-38]. Niewczas and Hoagland [39] predicted the deconstruction of SFTs by mobile TBs in Cu by atomistic sim ulations. Recently, we have reported in situ observations of the removal of SFTs by nanotwins in $\mathrm{Kr}$ ion irradiated $\mathrm{nt} \mathrm{Ag}$ [40, 41]. A twin boudnary affected zone was also disovered wherein time accumulative defect density and defect diffusivity were substantially different from those in twin interior [42]. Furtherm ore we show that deliberate introduction of na novoids in conjunction with nanotwins enables significantly enhanced damage tolerance in $\mathrm{nt} \mathrm{Cu}$. TBs can provide fast diffusion channels for raidaiton induced defects, and na novoids store and annihilate a la rge number of defect clusters. As a result, instead of experien cing void growth (or void swelling) that are frequently observed 
in irradiated conventional metals, these pre-existing voids at twin boundaries shrink by absorbing radiation induced interstitial loops as revealed by in situ $\mathrm{Kr}$ ion irradiation studies [43].

Radiation damage in $\mathrm{Cu}$, as a m odel system, has been intensely investigated by both $e x$ situ [44], [45] and in situ radiaiton experiments [46, 47]. As Cu has a low stacking fault energy, a majority of the rad iation induced defects are SF Ts $[3,8]$. Susequently, system atic studies were reported on the form ation of SFTs [48-50] a nd destruction/anniliation of SFTs by $m$ obile dislocations [51-55]. The role of TBs in Cu has been scatterly discussed in literature [38, 45, 47]. In order to further elucidate the interaction of defect clus ters with TBs, we perfor med in situ $\mathrm{Kr}$ ion irradiation studies on cross- sectional specimens of $\mathrm{nt} \mathrm{Cu}$ inside a transm ission electron microscope. Our in situ studies provide ample evidence for defect-TB interactions, including the absorption of defect clusters by TB s. Furthermore our statistical studies show that the defect life time is drastically chan ged when they are adjacent to $T$ Bs, lending further support for the significance of TBs on removal of defect clusters in metals.

\section{Experimental}

$\mathrm{Cu}$ films were deposited on HF etched $\mathrm{Si}$ (110) substrates using the magnetron sputtering technique at room temperature. The chamber was evacuated to a base pressure of less than $8 \times 10^{-}$

${ }^{8}$ torr prior to deposition. The total film thickness was $\sim 1 \mu \mathrm{m}$ for $\mathrm{nt} \mathrm{Cu}$ and $\sim 20 \mu \mathrm{m}$ for coarse grained (cg) $\mathrm{Cu}$. The deposition rate was $\sim 0.5 \mathrm{~nm} / \mathrm{s}$. $\mathrm{Cg} \mathrm{Cu}$ film was pe eled off from substrates after deposition and annealed in vacuum of less than $6 \times 10^{-7}$ torr at $300^{\circ} \mathrm{C}$ for $1 \mathrm{~h}$, followed by subsequent furnace cooling. Cross-sectional transmission electron microscopy (XTEM) samples 
were prepared by di mpling and lo w energy ( $3.5 \mathrm{keV}$ ) Ar ion $\mathrm{m}$ illing and subsequent ion polishing.

In situ $\mathrm{Kr}^{++}$ion irradiation at $1 \mathrm{MeV}$ was performed for $\mathrm{cg}$ and $\mathrm{nt} \mathrm{Cu}$ at room temperature in the Inte rmediate Voltage E lectron Microscope (IVEM) at Argonne National Laboratory, where an ion accelerator was attached to a HITACHI H-9000NAR transm ission electron microscope. The microscope was operated at $200 \mathrm{kV}$ continuously during radiation in order to record the microstructural evolution. The average dose rate was $0.43-1.98 \times 10^{-3} \mathrm{dpa} \mathrm{s}^{-1}$. A CCD camera was used to capture $\mathrm{m}$ icrostructural evolution during radiation at 15 fram $\mathrm{es} \mathrm{s}^{-1}$. The Stopping and Range of Ions in Matter (SRIM) s imulation was used to estimate the displacement damage profile and $\mathrm{Kr}^{++}$ion distribution [56]. High resolution TEM (HRTEM) experiments were performed using an FEI Tecnai G2 F20 microscope operated at $200 \mathrm{kV}$. The density and size of radiation induced defects at each in dividual radiation dose shown in Fig. 4 were measured by using three TEM micrographs with the size of $\sim 200 \times 200 \mathrm{~nm}^{2}$. The error bars were determined by standard deviations. In Fig. 7 and Fig. 8, for the stage 1, the statistical data of defect life time for both $\mathrm{cg}$ and $\mathrm{nt} \mathrm{Cu}$ were collected from the dose range of $0-0.025 \mathrm{dpa}$; in the stage 2, the statistical data of defect life time for both $\mathrm{cg}$ and nt $\mathrm{Cu}$ we re collected over the dose of 1.4-1.5 dpa. Error bars for defect lifetime were determined from standard deviation.

\section{Results}

Fig. 1 shows the $\mathrm{m}$ icrostructural evolution of $\mathrm{cg} \mathrm{Cu}$ subjected to $\mathrm{Kr}$ ion irradiation. The as-annealed $\mathrm{cg} \mathrm{Cu}$ (Fig.1 a) contained little growth defects, which were formed during sputtering deposition. The defect density drastically increased after radiation to a low dose of $\sim 0.01 \mathrm{dpa}$, as 
shown in Fig. 1b. The a verage defect size was $\sim 6.5 \mathrm{~nm}$. Radiation led to continuous growth of defect clusters, some of which had dim ensions of $20 \mathrm{~nm}$ by 0.05 dpa as shown in Fig. 1c. By $1.56 \mathrm{dpa}$, large defect clusters as well as dislo cation segments were frequently observed as labeled in Fig. 1d.

In comparison, nt $\mathrm{Cu}$ exhibited significantl y different morphology. High-density growth twins with $\Sigma 3\{111\}$ coherent twin boundaries (CTBs) and $\Sigma 3\{112\}$ incoherent twin boundaries (ITBs) were observed in as-deposited nt $\mathrm{Cu}$ (Fi g. 2a), showing an average twin thickness of $\sim 15$ nm. Although there were a few growth defects in the as-deposited specimen, the increment rate of defect density was significantly lower than that in cg Cu. Up to $0.1 \mathrm{dpa}$, the defect density remained low as shown in Fig. 2b. By 0.56 dpa, radiation triggered extensive interaction between TBs and defect clusters and led to the formation of stacking faults (SFs) at TBs as shown in Fig. 2c. By 1.56 dpa little dislocation segments were observed (Fig. 2d).

Fig. 3 compares defect morphology am ong cg Cu (Fig. 3a), thick twinned $\mathrm{Cu}$ (Fig. 3b) and fine twinned $\mathrm{Cu}$ (Fig. 3c). After radiation, $\quad \mathrm{cg} \mathrm{Cu}$ (Fig. 3a) contained very large defect clusters $(\sim 20 \mathrm{~nm}$ in size). In thick twinned $\mathrm{Cu}$, abundant defect cluste rs were observed, which were mainly in the form of intact SFTs (Fig. 3b2). In the irradiated fine nt $\mathrm{Cu}$, truncated SFTs as outlined in Fig. $3 \mathrm{c} 2 \mathrm{w}$ ere frequently observed near TBs. Furthermore SFs were identified adjacent to the TBs. Correspondingly the streaking lines in the inset fast Fourier transform (FFT) of the image also confirm the formation of SFs.

Comparison of the defect density in the cg a nd $\mathrm{nt} \mathrm{Cu}$ is shown in Fig. 4a. In both cases, defect density increased rapidly in the early radi ation stage (stage 1) and then reached a plateau (in stage 2). Several significant differences were also noted. (1) In the stage 1, the in crement rate 
of defect density in $\mathrm{cg} \mathrm{Cu}$ is $\mathrm{m}$ uch higher than that in $\mathrm{nt} \mathrm{Cu}$. (2) The saturation defect density in nt $\mathrm{Cu}$ is $\sim 50 \%$ of that in $\mathrm{cg} \mathrm{Cu}$. Comparison of the distributions of defect dimension in Fig. $4 \mathrm{~b}$ (up to $1.56 \mathrm{dpa}$ ) shows that $\mathrm{cg} \mathrm{Cu}$ has a broad range of defect si ze, varying from 2-17 nm, with an average dimension of $\sim 6 \mathrm{~nm}$. In contrast $\mathrm{nt} \mathrm{Cu}$ has an average defect size of $\sim 3 \mathrm{~nm}$, with a smaller size distribution, in the range of 1-9 $\mathrm{nm}$.

In situ snapshots in Fig. 5 (see Supplementary Video S1) illustrate the formation of large defect clusters in $\mathrm{cg} \mathrm{C}$ u. The initial dislocation segment 1 (Fig. 5a) interacted with the newly formed segment 2 (Fig. 5b) by 7s. The two intersecting dislocation segments absorbed peripheral defects continuously to form a larger dislocation tangles (Fig. 5c) by $31 \mathrm{~s}$. The dislocation tangle eventually evolved into a large circular defect cluster (Fig. 5d).

In contrast the evolution of de fect clusters in $\mathrm{nt} \mathrm{Cu}$ is clearly curtailed by TBs. In situ videos captured direct and representative evidence for the absorption of dislocation loops by TBs during radiation of the nt $\mathrm{Cu}$ over 0.3-0.4 dpa (s ee Supplementary Video S2). As shown in Fig. 6a, a radiation induced dislocation loop with $\sim 4 \mathrm{~nm}$ in diameter was located in the middle of a laminate between two TBs. In $0.1 \mathrm{~s}$, the loop m igrated by nearly $4 \mathrm{~nm}$ towards the TB (Fig. 6b). Interestingly the loop was not immediately absorb ed by the TB and it did not grow either during continuous radiation. After $8 \mathrm{~s}$, the loop was merely $3 \mathrm{~nm}$ away from the TB (Fig. $6 \mathrm{c}$ ) and nearly contacted the TB by $8.2 \mathrm{~s}$ (Fig. $6 \mathrm{~d}$ ). The loop was then in full contact with the TB and became smaller by $9.1 \mathrm{~s}$ (Fig. 6e). Finally by $11.2 \mathrm{~s}$, the entire loop was annihilated by the TB.

The kinetics of de fect evolution in $\mathrm{nt} \mathrm{Cu}$ was studied by exam ination of hundreds of defect clusters from the in situ radiation videos. Within a certain range of radiation dose, the migration behaviors of a large number (hundre ds) of newly generated defects were tracked 
individually and manually to obtain the location and life time of these defects. In particular, the life time of defect clusters as a function of their distances to TBs is plotted in Fig. 7. In the stage 1, the average defect lif e time is $\sim 19 \mathrm{~s}$ with insignificant dependence on the distance to TB, although the defect life time appears to decrease slightly to $10 \mathrm{~s}$ when they are very close (within $5 \mathrm{~nm}$ ) to the TBs. In the stage 2, the average defect life time decreases sharply to $4 \mathrm{~s}$, with little dependence on their distance to TBs (when the separation distance is $20 \mathrm{~nm}$ or less).

Meanwhile, the life tim e of defect clusters in the stage 2 as a functi on of defect size is compared between the cg and $\mathrm{nt} \mathrm{Cu}$. As shown in Fig. 8, the $\mathrm{nt} \mathrm{Cu}$ with smaller defect cluster size 1-5 nm) has a very short average defect life time, $\sim 4 \mathrm{~s}$. However, the average life tim e of defect clusters $(5-11 \mathrm{~nm})$ in $\mathrm{cg} \mathrm{Cu}$ is $\sim 15 \mathrm{~s}$. The average life time and defect sizes for the cg and nt $\mathrm{Cu}$ are s ummarized in Table 1 . The corresponding accumulated dose of life tim e of defect clusters is also provided.

\section{Discussion}

\subsection{Formation of SFTs and loops}

Interstitial clusters can transform into faulted Frank loops and pe rfect loops[57], while vacancy clusters are in the form of SFTs and Frank loops on $\{111\}$ planes [49]. The energy of a mixed dislocation loop can be calculated by $[7,58]$

$$
E_{\text {loop }}=\frac{\mu b_{e}^{2} r_{L}}{2(1-v)} \ln \left[\frac{2 r_{L}}{r_{0}}\right]+\frac{\mu b_{s}^{2} r_{L}}{2(1-v)}\left(1-\frac{v}{2}\right) \ln \left[\frac{2 r_{L}}{r_{0}}\right]
$$


where the first term on the right corresponds to the elastic energy of a c ircular edge loop with radius $r_{L}$ in an isotropic solid with Burgers vector $b_{e}$, and the second term is the elastic energy of a screw loop with Burgers vector $b_{s}$. The cut-off distance here is $2 r_{L}$ because the stress fields of dislocation segments on opposite sides of a loop cancel at a distance of $\sim 2 r_{L}$. For the pe rfect loop, $b=1 / 2<110>$, so that $b_{e}^{2}=a^{2} / 3$ and $b_{s}^{2}=a^{2} / 6$. For the Frank loop, $b_{e}^{2}=a^{2} / 3$ and $b_{s}^{2}=0$. In addition, the Frank loop contai ns a stacking fault with energy of $\pi r^{2} \gamma_{S F}$, where $\gamma_{S F}$ is stacking fault energy, $\sim 55 \mathrm{~mJ} / \mathrm{m}^{2}$ for $\mathrm{Cu}[59]$. For $\mathrm{Cu}, \mu=48 \mathrm{GPa}, b=0.256 \mathrm{~nm}, v=0.34$. The relationship between $r_{L}$ with certain number of vacancies/interstitials (n) is $r_{L}=\left(\frac{\sqrt{3} a^{2} n}{4 \pi}\right)^{1 / 2}$

where a is the lattice parameter $(3.615 \AA$ for $\mathrm{Cu})$.

Now we can compare the calculated energy of a perfect and Frank di slocation loop as a function of the loop size (rep resented by the $\mathrm{n}$ umber of vacancies/interst itials) in the defect cluster. As shown in Fig. 9, when the radius of a loop ( $r_{\text {loop }}$ ) is less than $16 \mathrm{~nm}$, the energy of a Frank loop $\left(E_{f}\right.$, represented by the blue dash-dotted line) is comparable to or slightly lower than that of a perfect loop ( $E_{p}$, shown as the solid red line), indicating that Frank loops may be m ore stable than perfect loops in $\mathrm{Cu}$. In this study, $\mathrm{m}$ ost of defect clusters have radius sm aller than 16 $\mathrm{nm}$, therefore the formation of Frank loops is energetically favorable.

Next we probe the formation of SFTs. The energy of an SFT can be estimated by [7] 
$E_{S F T}=\frac{\mu L b^{2}}{6 \pi(1-v)} \ln \left[\left(\frac{4 L}{a}\right)+1.017+0.97 v\right]+\sqrt{3} L^{2} \gamma_{S F}$

where $\mathrm{L}$ is the ledge length of an SFT and can be written as

$L=a(n / 3)^{1 / 2}$

Here a and $n$ carry the same meaning as defined previously. As shown by the black solid line in Fig. 9, the energ y of SFTs is much lower than $E_{F}$ and $E_{P}$, implying that the formation of SFTs is energetically favorable over Frank and perfect dislocatio $n$ loops, consistent with our in situ TEM observations.

\subsection{Kinetics of defect clusters - defect life time}

The difference between the life tim es of defect clusters in $\mathrm{nt} \mathrm{Cu}$ in the two stages ( as shown in Fig. 7) indicates that TB s play a significant role in the defect removal process. During the initial radiation process (stage 1), defect density is low and de fect clusters seldom interact with TBs or among themselves. Consequently the life time of defect clusters is relatively long, $19 \mathrm{~s}$. In stage 2 , the high defect density in twin in terior prompts these defect clusters to interact actively and frequently with the TBs. The fre quent annihilation of th ese defect clusters substantially reduces the ir life time, to $\sim 4 \mathrm{~s}$. Furthermore the life tim e (in stage 2 ) of defect clusters in nt specim en is much lower than th at in cg sp ecimen $(\sim 15 \mathrm{~s})$, consiste nt with the observation of the enhanced defect absorption/interactions with high-density TBs.

The kinetics of defect $\mathrm{m}$ igration has been ev aluated in $\mathrm{nt} \mathrm{Ag}$ with large aver age twin spacing ( $70 \mathrm{~nm})$ via in situ studies [42]. In general the globa 1 diffusivity of defect clusters (determined by averaging accumulative diffusion distance over a defect's lifetime) in the center 
zone of twins (further away from TBs) is higher than those adjacent to TBs. As the defect density in twin interior is greater than those near TBs (but not in the TB affected zones), there are more interactions (migration) among defect clusters in the center of a twinned lam inate, and consequently increasing the global diffusivity of th ese defect clusters. The scenario is sligh tly different in the current $\mathrm{nt} \mathrm{Cu}$. As the average twin spacing of $\mathrm{nt} \mathrm{Cu}$ is $\sim 15 \mathrm{~nm}$, comparable to the width of TB affected zones, $\sim 5 \mathrm{~nm}$ as observed in irradiated $\mathrm{nt} \mathrm{Ag}$ [ 42], the influence of T B affected zones dominates in the current studies. As the migration distances of defect clus ters in the TB affected zones are typically sm all, it is difficult to obtain a reliable $m$ easurement of the global diffusivity of defect clusters in $\mathrm{nt} \mathrm{Cu}$.

In the early stage of radiati on process (stage 1), we observed that $43 \%$ of defect clusters nucleated at TBs. Two possible mechanisms might be responsible for this phenomenon. Firstly, a greater amount of interstitials prefer to nucleate at TBs due to collision sequences. $<110>$ direction in a $\mathrm{m}$ atrix is parallel to $<411>$ in a twin, which is not favorable for crowdion formation [60]. Crowdi ons with $<110>$ orie ntation, which do not lie on the $\{111\}$ twinning planes, cannot propagate across TBs. Secondly, th e formation energy of a/3<111> Frank loop is lower on TBs than that in matrix [47]. We use a TB with the stacking sequence of ABCACBA as an example, where the TB is underlined. Inserting an extra $\{111\}$ plane (B in the bracket), the stacking sequence would becom e $\mathrm{ABC}(\mathrm{B}) \underline{\mathrm{ACBA}}$, and we can rewrite it as $\mathrm{ABC}(\mathrm{B}) \mathrm{ACBA}$, where $\mathrm{C}$ is the new TB location. $\mathrm{T}$ hus instead of causing stacking faults, we can consider this case as a slight $\mathrm{m}$ igration of the TB. The fre quent migration of TBs would also enhance the interaction of TBs with defect clusters, e.g. SFTs. Note that co alescence and annihilation of the loops would be preferred near TBs, as these lo ops in twinning planes share the same Burgers vector. 


\subsection{Elimination of SFTs by TBs and the evolution of TB morphology}

Now we examine the interaction between TBs and SFTs in the nt $\mathrm{Cu}$. MD simulations have illustrated possible mechanisms leading to the destruction of an SFT by CTB [39], which was later observed experim entally in $\mathrm{Kr}$ ion irra diated $\mathrm{nt} \mathrm{Ag}$ [41], that is SFTs induced by radiation could be destructed from their bases by interaction with TBs. Here we propose that this mechanism could also be applied to the case where TBs are decorated by SFs.

The HRTEM micrograph in Fig. 10a and the corresponding schematics in Fig. 10b show, after radiation, a partially truncated SFT is sandwiched between TBs, which are decorated by SF ribbons. The base of the SFT adjacent to the SF ribbon is partially removed during radiation. The mechanism of SF-SFT interact ion can be explained via schem atics in Fig.10c-d. The SFT contains numerous stair-rod dislocations, $\mathrm{AB}, \mathrm{AC}$, and $\mathrm{BC}$, with Burgers vectors of $a / 6<110>$. The arrows indicate the directions of the dislocation lines. W hen a Shockley partial $a / 6[121]$ reaches the SF T from its base plane, it inte racts with the three s tair-rod dislocations via the following reactions:

$$
\begin{aligned}
& \frac{a}{6}[1 \overline{1} 0]+\frac{a}{6}[121]=\frac{a}{6}[211] \quad(\text { along } \mathrm{AB}) \\
& \frac{a}{6}[0 \overline{1} 1]+\frac{a}{6}[121]=\frac{a}{6}[112] \quad(\text { along } \mathrm{AC}) \\
& \frac{a}{6}[101]+\frac{a}{6}[121]=\frac{a}{3}[111] \quad(\text { along } \mathrm{BC})
\end{aligned}
$$

After reactions, two new Shockley partials, $\frac{a}{6}$ [211] and $\frac{a}{6}$ [112], are generated on the SFT surface plane ABD (1 $\overline{1} \overline{1})$ along $\mathrm{AB}$ and on $\mathrm{ACD}(\overline{1} \overline{1} 1)$ along $\mathrm{AC}$. The two partials are free 
to move on their slip planes, resulting in the unzipping (destruction) of the SFT, shrinkage of the stair-rod dislocation $\mathrm{AD}$, and eventually the collapse of the SFT.

\subsection{Creation of ITBs during CTB-dislocation loop interactions}

There is a comm on anticipation that the de fect sink strength of grain boundaries scales with the energy of grain boundaries, that is in general high angle grain boundaries are $\mathrm{m}$ ore effective defect sinks than low angle grain boundaries. Consequently it is commonly adopted that CTBs in fcc $m$ etals are less effective defect sinks. There are recent experim ental evidence derived from void denuded zones (VDZ) along grain boundaries that support such a hypothesis [38]. On the other hands, there are scattered evidence that shows that TBs are defect sinks. Segall [61] showed CTBs are biased sinks for vacancies in quenched Al. Kin g and Sm ith [47] have proposed that CTBs may be sinks for di slocation loops in $\mathrm{Al}$ and $\mathrm{Cu}$ during in situ high-voltage electron radiation. In this study we notice that CT Bs interact frequently with dislocation loops and such intensive interactions lead to several consequences.

First, abundant ITBs are generated along CTBs, and in som e cases forming curved TBs consisting of a com bination of miniscule ITBs and CTBs as observed in irradiated nt Ag [42]. ITBs are effective defect sinks that accommodate (store) radiation induced defects as the regular high angle grain boundaries do. Additionally the ITBs can effectively transport po int defects as MD simulations show defects can easily $\mathrm{m}$ igrates along certain ITB channels [43]. Meanwhile ITBs contain a high density of $m$ obile partials [62-64], which can acti vely sweep and engage defect clusters in irrad iated twinned metals. Previous studies also show that the intera ction of dislocations with CTBs in $\mathrm{nt} \mathrm{m}$ etals under external stresses can in troduce abundant ITBs along 
CTBs [65-67]. Furthermore the radiation induced migration of ITBs also arises from the mobility of these Shockley partials.

Second, under external stresses some dislocations (such as Shockley partials, and perfect dislocations) that interact with CTBs [65] may cross-slip on the CTB, le aving mobile Shockley partials on the twinning plane. As m entioned earlier, the abunda nt Shockley partials on the twinning planes can s ignificantly increase the probability of annihilation of radiation induced defect clusters. Finall $\mathrm{y}$ the form ation of SFs after destru ction of SFTs along TBs $\mathrm{m}$ ay also enlarge the TB affected zone and accelerate the removal of defect clusters. These statements are consistent with our experim ental observations, which show no dislocation segm ents, less and smaller defects, and lower defect life time in irradiated nt $\mathrm{Cu}$ with an average twin spacing of 15 nm.

It is worth noting that radiation induced loca 1 stress could also prom ote the migration of radiation induced dislocations by confined layer slip, which woul d increase the odds for perfect dislocation-SFT interactions and subsequent destruction of SFTs.

\section{Conclusions}

In situ $\mathrm{Kr}$ ion irradiation studies were performed on coarse grained $\mathrm{Cu}$ and nanotwinned $\mathrm{Cu}$ with an average twin spacing of $\sim 15 \mathrm{n}$ m. Major findings include the followings: 1) Nanotwinned $\mathrm{Cu}$ exhibits enhanced irradiation tolerance in terms of smaller defect size and lower defect density; 2) TBs ac tively absorb radiation induced defect clusters. 3) TBs destruct SFTs and lead to the for mation of SFs along TBs; 4) Incoherent twin boundaries $m$ igrate frequently during radiation as th ese boundaries contain hi gh-density mobile partials; 5) Defect clusters in nanotwinned $\mathrm{m}$ etals have much shorter life time than those in coarse grained $\mathrm{Cu}$. 
These evidence suggests that nanotwins are highly efficient defect sinks that may significantly enhance the radiation tolerance in metallic materials.

\section{Acknowledgements}

We acknowledge financial support by NSF-DM R-Metallic Materials and Nanostructures Program under grant no. 1304101. Y Chen is supported financially by NSF-CMMI 1161978. KY $\mathrm{Yu}$ and the work on fa brication of nanotwinned metal were supported by DOE-OBES under grant no. DE-SC0010482. XZ and HW also acknow ledge the seed grants from Texas A\&M University on studying of $\mathrm{m}$ aterials in extreme environments via in situ techniques. $\mathrm{W}$ e also thank Peter M. Baldo and Edward A. Ryan at Argonne National Laboratory for their help during in situ irradiation experim ents. The electron microscopy with in situ ion irradiation was accomplished at Argonne National Laboratory at the IVEM-Tandem Facility, a U.S. Department of Energy Facility funded by the DOE Office of Nuclear Energy, operated under Contract No. DE-AC02-06CH11357 by U Chicago, Argonne, LLC. Accesses to the DOE - Center for Integrated Nanotechnologies (CIN T) at Los Alam os and Sandi a National Laboratories and Microscopy and Imaging Center at Texas A\&M University are also acknowledged.

\section{References}

1. J. B. Gibson, A. N. Goland, M. Milgram et al., Dynamics of Radiation Damage, Phys. Rev. 120 (1960) 1229.

2. S. J. Zinkle, L. E. Seitzman,W. G. Wolfer, I. Energy calculations for pure metals, Philos. Mag. A 55 (1987) 111.

3. B. N. Singh,S. J. Zinkle, Defect accumulation in pure fcc metals in the transient regime: a review, J. Nucl. Mater. 206 (1993) 212. 
4. B. N. Singh, S. I. Golubov, H. Trinkaus et al., Review: evolution of stacking fault tetrahedra and its role in defect accumulation under cascade damage conditions, J. Nucl. Mater. 328 (2004) 77.

5. D. J. Bacon, F. Gao,Y. N. Osetsky, The primary damage state in fcc, bcc and hcp metals as seen in molecular dynamics simulations, J. Nucl. Mater. 276 (2000) 1.

6. W. J. Phythian, R. E. Stoller, A. J. E. Foreman et al., A comparison of displacement cascades in copper and iron by molecular dynamics and its application to microstructural evolution, J. Nucl. Mater. 223 (1995) 245.

7. G. S. Was, Fundamentals of radiation materials science: metals and alloys, Springer-Verlag Berlin Heidelberg, 2007.

8. M. Victoria, N. Baluc, C. Bailat et al., The microstructure and associated tensile properties of irradiated fcc and bcc metals, J. Nucl. Mater. 276 (2000) 114.

9. G. R. Odette,G. E. Lucas, Embrittlement of nuclear reactor pressure vessels, JOM 53 (2001) 18.

10. Z. Yao, R. Schäublin,M. Victoria, The microstructure and tensile properties of pure Ni single crystal irradiated with high energy protons, J. Nucl. Mater. 307-311, Part 1 (2002) 374.

11. L. L. Hsiung, M. J. Fluss, S. J. Tumey et al., Formation mechanism and the role of nanoparticles in Fe-Cr ODS steels developed for radiation tolerance, Phys. Rev. B 82 (2010) 184103.

12. G. R. Odette,D. T. Hoelzer, Irradiation-tolerant nanostructured ferritic alloys: Transforming helium from a liability to an asset, JOM 62 (2010) 84.

13. C. Sun, M. Song, K. Y. Yu et al., In situ evidence of defect cluster absorption by grain boundaries in Kr ion irradiated nanocrystalline Ni, Metall. Mater. Trans. A 44 (2013) 1966.

14. O. El-Atwani, J. Hinks, G. Greaves et al., In-situ TEM observation of the response of ultrafine-and nanocrystalline-grained tungsten to extreme irradiation environments, Sci. Rep. 4 (2014).

15. X.-M. Bai, A. F. Voter, R. G. Hoagland et al., Efficient annealing of radiation damage near grain boundaries via interstitial emission, Science 327 (2010) 1631.

16. D. Chen, J. Wang, T. Chen et al., Defect annihilation at grain boundaries in alpha-Fe, Sci. Rep. 3 (2013) 1450.

17. B. N. Singh, Effect of grain size on void formation during high-energy electron irradiation of austenitic stainless steel, Philos. Mag. 29 (1974) 25.

18. B. N. Singh,A. J. E. Foreman, Calculated grain size-dependent vacancy supersaturation and its effect on void formation, Philos. Mag. 29 (1974) 847.

19. R. B. Adamson, W. L. Bell,P. C. Kelly, Neutron irradiation effects on copper at $327^{\circ}$ C, J. Nucl. Mater. 92 (1980) 149.

20. R. W. Siegel, S. M. Chang,R. W. Balluffi, Vacancy loss at grain boundaries in quenched polycrystalline gold, Acta Metall. 28 (1980) 249.

21. M. Dollar,H. Gleiter, Point defect annihilation at grain boundaries in gold, Scripta Metall. 19 (1985) 481.

22. S. J. Zinkle,K. Farrell, Void swelling and defect cluster formation in reactor-irradiated copper, J. Nucl. Mater. 168 (1989) 262.

23. W. Z. Han, M. J. Demkowicz, E. G. Fu et al., Effect of grain boundary character on sink efficiency, Acta Mater. 60 (2012) 6341.

24. W. Han, M. J. Demkowicz, N. A. Mara et al., Design of radiation tolerant materials via interface engineering, Adv. Mater. 25 (2013) 6975.

25. M. Song, Y. D. Wu, D. Chen et al., Response of equal channel angular extrusion processed ultrafine-grained T91 steel subjected to high temperature heavy ion irradiation, Acta Mater. 74 (2014) 285.

26. R. L. Klueh,A. T. Nelson, Ferritic/martensitic steels for next-generation reactors, J. Nucl. Mater. 371 (2007) 37. 
27. F. A. Garner, M. B. Toloczko,B. H. Sencer, Comparison of swelling and irradiation creep behavior of fcc-austenitic and bcc-ferritic/martensitic alloys at high neutron exposure, J. Nucl. Mater. 276 (2000) 123.

28. G. Odette, M. Alinger,B. Wirth, Recent developments in irradiation-resistant steels, Annu. Rev. Mater. Res. 38 (2008) 471.

29. S. Ukai,M. Fujiwara, Perspective of ODS alloys application in nuclear environments, J. Nucl. Mater. 307-311, Part 1 (2002) 749.

30. I. J. Beyerlein, A. Caro, M. J. Demkowicz et al., Radiation damage tolerant nanomaterials, Mater. Today 16 (2013) 443.

31. M. J. Demkowicz, A. Misra,A. Caro, The role of interface structure in controlling high helium concentrations, Curr. Opin. Solid State Mater. Sci. 16 (2012) 101.

32. A. Misra, M. J. Demkowicz, X. Zhang et al., The radiation damage tolerance of ultra-high strength nanolayered composites, JOM 59 (2007) 62.

33. X. Zhang, E. G. Fu, N. Li et al., Design of radiation tolerant nanostructured metallic multilayers, J. Eng. Mater. Technol. 134 (2012) 041010.

34. X. Zhang, E. G. Fu, A. Misra et al., Interface-enabled defect reduction in He ion irradiated metallic multilayers, JOM 62 (2010) 75.

35. J. W. Christian,S. Mahajan, Deformation twinning, Prog. Mater Sci. 39 (1995) 1.

36. Y. T. Zhu, X. Z. Liao,X. L. Wu, Deformation twinning in nanocrystalline materials, Prog. Mater Sci. 57 (2012) 1.

37. L. Lu, Y. Shen, X. Chen et al., Ultrahigh Strength and High Electrical Conductivity in Copper, Science 304 (2004) 422.

38. M. J. Demkowicz, O. Anderoglu, X. Zhang et al., The influence of $\Sigma 3$ twin boundaries on the formation of radiation-induced defect clusters in nanotwinned Cu, J. Mater. Res. 26 (2011) 1666.

39. M. Niewczas,R. G. Hoagland, Molecular dynamic studies of the interaction of $a / 6<112>$ Shockley dislocations with stacking fault tetrahedra in copper. Part II: Intersection of stacking fault tetrahedra by moving twin boundaries, Philos. Mag. 89 (2009) 727.

40. K. Y. Yu, D. Bufford, F. Khatkhatay et al., In situ studies of irradiation-induced twin boundary migration in nanotwinned Ag, Scripta Mater. 69 (2013) 385.

41. K. Y. Yu, D. Bufford, C. Sun et al., Removal of stacking-fault tetrahedra by twin boundaries in nanotwinned metals, Nat. Commun. 4 (2013) 1377.

42. J. Li, K. Y. Yu, Y. Chen et al., In situ study of defect migration dinetics and self-healing of twin boundaries in heavy ion irradiated nanotwinned metals, Nano Lett. 15 (2015) 2922.

43. Y. Chen, K. Y. Yu, Y. Liu et al., Damage-tolerant nanotwinned metals with nanovoids under radiation environments, Nat. Commun. 6 (2015) 7036.

44. S. Kojima, S. J. Zinkle,H. L. Heinisch, Radiation hardening in neutron-irradiated polycrystalline copper: Barrier strength of defect clusters, J. Nucl. Mater. 179 (1991) 982.

45. N. Li, J. Wang, Y. Q. Wang et al., Incoherent twin boundary migration induced by ion irradiation in Cu, J. Appl. Phys. 113 (2013) 023508.

46. N. Li, K. Hattar,A. Misra, In situ probing of the evolution of irradiation-induced defects in copper, J. Nucl. Mater. 439 (2013) 185.

47. A. H. King,D. A. Smith, On the mechanisms of point-defect absorption by grain and twin boundaries, Philos. Mag. A 42 (1980) 495.

48. J. Silcox,P. B. Hirsch, Direct observations of defects in quenched gold, Philos. Mag. 4 (1959) 72.

49. T. Kadoyoshi, H. Kaburaki, F. Shimizu et al., Molecular dynamics study on the formation of stacking fault tetrahedra and unfaulting of Frank loops in fcc metals, Acta Mater. 55 (2007) 3073.

50. B. D. Wirth, V. Bulatov, T. Diaz de la Rubia, Atomistic simulation of stacking fault tetrahedra formation in Cu, J. Nucl. Mater. 283-287, Part 2 (2000) 773. 
51. B. D. Wirth, V. Bulatov,T. D. de la Rubia, Dislocation-stacking fault tetrahedron interactions in Cu, J. Eng. Mater. Technol. 124 (2002) 329.

52. M. Hiratani, H. M. Zbib,B. D. Wirth, Interaction of glissile dislocations with perfect and truncated stacking-fault tetrahedra in irradiated metals, Philos. Mag. A 82 (2002) 2709.

53. J. S. Robach, I. M. Robertson, H. J. Lee et al., Dynamic observations and atomistic simulations of dislocation-defect interactions in rapidly quenched copper and gold, Acta Mater. 54 (2006) 1679.

54. Y. Matsukawa,S. J. Zinkle, Dynamic observation of the collapse process of a stacking fault tetrahedron by moving dislocations, J. Nucl. Mater. 329-333, Part B (2004) 919.

55. Y. N. Osetsky, D. Rodney,D. J. Bacon, Atomic-scale study of dislocation-stacking fault tetrahedron interactions. Part I: mechanisms, Philos. Mag. 86 (2006) 2295.

56. J. F. Ziegler,J. P. Biersack, SRIM-2008, Stopping Power and Range of lons in Matter, (2008).

57. Y. N. Osetsky, D. J. Bacon, B. N. Singh et al., Atomistic study of the generation, interaction, accumulation and annihilation of cascade-induced defect clusters, J. Nucl. Mater. 307-311, Part 2 (2002) 852.

58. D. Hull,D. J. Bacon, Introduction to dislocations, Pergamon Press Oxford, 1984.

59. P. C. J. Gallagher, The influence of alloying, temperature, and related effects on the stacking fault energy, Metall. Trans. 1 (1970) 2429.

60. R. A. Johnson, Physics of Radiation Effects in Crystals, Elsevier Science Ltd, 1986.

61. R. Segall, Coherent annealing twin boundaries as vacancy sinks, Acta Metall. 12 (1964) 117.

62. J. Wang, N. Li, O. Anderoglu et al., Detwinning mechanisms for growth twins in face-centered cubic metals, Acta Mater. 58 (2010) 2262.

63. J. Wang, N. Li,A. Misra, Structure and stability of $\Sigma 3$ grain boundaries in face centered cubic metals, Philos. Mag. 93 (2013) 315.

64. J. Wang, O. Anderoglu, J. P. Hirth et al., Dislocation structures of $\Sigma 3\{112\}$ twin boundaries in face centered cubic metals, Appl. Phys. Lett. 95 (2009) 021908.

65. Y. T. Zhu, X. L. Wu, X. Z. Liao et al., Dislocation-twin interactions in nanocrystalline fcc metals, Acta Mater. 59 (2011) 812.

66. Z. H. Jin, P. Gumbsch, K. Albe et al., Interactions between non-screw lattice dislocations and coherent twin boundaries in face-centered cubic metals, Acta Mater. 56 (2008) 1126.

67. Y. M. Wang, F. Sansoz, T. LaGrange et al., Defective twin boundaries in nanotwinned metals, Nat. Mater. (2013). 


\section{Figure and Table Captions}

Table 1. A summary of defect sizes and life time and corresponding doses in stages 1 and 2 for $\mathrm{nt}$ and $\operatorname{cg~} \mathrm{Cu}$.

Fig. 1. Bright field XTEM $\mathrm{m}$ icrographs showing the evolution of defects during in situ $\mathrm{Kr}$ ion irradiation of coarse grained (cg) $\mathrm{Cu}$, up to a dose of $1.56 \mathrm{dpa}$. (a) The as-annealed $\mathrm{Cu}$ had a very low density of defect clusters. (b) At 0.01 dpa, the density of defect clusters increased rapidly. (c) Radiation to 0.05 dpa led to a signif icant increase of defect density and prom inent enlargement of the dimension of defect clusters. (d) By $1.56 \mathrm{dpa}$, a large number of dislocation segments and large defect clusters appeared as marked by arrows in the figure.

Fig. 2. Bright-field $X$ TEM micrographs illustrating the microstructural evolution of the nanotwinned (nt) $\mathrm{Cu}$, irradiated by $\mathrm{Kr}$ ions up to $1.56 \mathrm{dpa}$. (a) The as-deposited nt $\mathrm{Cu}$ has an average twin thickness of $\sim 15 \mathrm{~nm}$. (b) At $0.1 \mathrm{dpa}$, defects accumulated moderately both along twin boundaries (TBs) and within twins/m atrices. (c) At $0.56 \mathrm{dpa}$, there is insignificant increase in density of defects compared to that at $0.1 \mathrm{dpa}$, while TBs were increasingly decorated by stacking faults (SFs). (d) At a higher irradia tion dose (1.56 dpa), sporadic dislocation loops appeared and little dislocation segments were observed.

Fig. 3. After irradiation to a dose of $1.56 \mathrm{dpa}$, higher magnification XTEM and high resolution TEM (HRTEM) images were recorded to examine de fects in both nt and $\mathrm{cg} \mathrm{Cu}$ in detail, along the $\mathrm{Cu}<110>$ zone axis. (a) In $\mathrm{cg} \mathrm{Cu}$, a larg e amount of defect cluste rs, including SFTs and dislocation segments, were observed. The inset selected area diffraction (SAD) pattern shows that the crystal structure rem ained single crystal after irradiation. A ring of dislocation segment consisting of large dislocation loops was shown in (a2). (b) In nt $\mathrm{Cu}$ at a location with lower twin density (or thicker twins), numerous SFTs were observed. (c) In $\mathrm{nt} \mathrm{Cu}$ with an av erage twinW KIFNQHWI QP VRFDOGIIQHWIQV WQ 6) 7V P DQ RI Z KIFKDSSHDUXQFDMG DOG6) V ZHHREVHYHGDOMFHQMKR $7 \% \mathrm{~V}$ 
Fig. 4. (a) A comparison on the evolution of defect density with dose between cg and nt $\mathrm{Cu}$. In the early stage (stage 1), the defect density increased rapidly with dose for both nt and cg $\mathrm{Cu}$, and it reached saturation at $\sim 0.1$ dpa in stage 2 . The defects counted in this study included SFTs and defect loops. The rate of defect multiplication and saturation density in $\mathrm{cg} \mathrm{Cu}$ were higher than those in $\mathrm{nt} \mathrm{Cu}$. (b) Radiation $\mathrm{i}$ nduced a narrow distribution of de fect size in $\mathrm{nt} \mathrm{Cu}$, with an average defect size of $\sim 3 \mathrm{~nm}$, compared with the greater average defect size of $\sim 6 \mathrm{~nm}$ in $\mathrm{cg} \mathrm{Cu}$ with a much broader size distribution.

Fig. 5. In situ observation of the formation of large defect clusters in cg $\mathrm{Cu}$ over a dose of 1.4-1.5 dpa. Dislocation segment 1 inte racted with the newly form ed segment 2 at 7 s. The two intersecting dislocation segments absorbed peripheral defects to form a larger defect cluster by $31 \mathrm{~s}$. By $33 \mathrm{~s}$, continuous absorption of surrounding defects led to the formation of a large defect cluster. (see Supplem entary Video S1 and the playing speed of th is video is accelerated by 3 times).

Fig. 6. In situ observation of loop absorption by TBs in nt Cu over a dose range of $0.3-0.4$ dpa. A radiation induced dislocation loop with a diam eter of approximately $4 \mathrm{~nm}$ was $8.5 \mathrm{~nm}$ away from the twin boundary. At $0.1 \mathrm{~s}$, the loop migrated towards the TB by approximately $4 \mathrm{~nm}$. In 8 $\mathrm{s}$, it migrated further slightly and the core of the loop was $\sim 3 \mathrm{~nm}$ from the TB. At $8.2 \mathrm{~s}$, the loop nearly contacted the TB. By 9.1s, the loop resid ed at the TB and became sm aller. By $11.2 \mathrm{~s}$, the entire loop was annihilated by th e TB (Supplementary Video S2 and the speed of this video has been accelerated by 3 times).

Fig. 7. Comparison of the life tim e of dislocation loops vs. their distance to TBs in irradiated nt $\mathrm{Cu}$ at two radiation stages. In stage $1(<0.1 \mathrm{dpa}$ as defined in Fig. 4a), the average life tim e of defect clusters is $19 \mathrm{~s}$. Howeve $\mathrm{r}$, in stage 2, the av erage life time of defect clu ster is $4 \mathrm{~s}$, substantially lower than that in stage 1 . For both stages, the life time of defect clus ters appears insensitive to their distance to the TBs (varying from 0 to $20 \mathrm{~nm}$ ).

Fig. 8. In the stage 2 during $\mathrm{Kr}$ ion irradiation, the defect life tim e in both nt and $\mathrm{cg} \mathrm{Cu}$ has insignificant dependence on defect size. However, th e average life time in $\mathrm{nt} \mathrm{Cu}$ is $\sim 4 \mathrm{~s}$, much shorter than that in $\mathrm{cg} \mathrm{Cu}, \sim 15 \mathrm{~s}$.

Fig. 9. The energy of dislocation loops (perfect and Frank loops) and SFTs increases with the number of vacancies contained in a defect cluster. When the radius of a loop is larger than $16 \mathrm{~nm}$, the energy of a perfect loop $\left(\mathrm{E}_{\mathrm{p}}\right)$ is less than that of a Frank loop $\left(\mathrm{E}_{\mathrm{F}}\right)$. The energy of SFTs is less than that of both types of loops in the calculated range.

Fig.10. (a) HRTEM m icrograph of an SFT in contact with TB-SFs complex in nt Cu. The SFT was partially destructed near its base. (b) The correspondi ng schematic of irradiated nt $\mathrm{Cu}$, including twins/matrices and SF ribbons near twins and in the matrices. (c) Schematic illustration of a Shockley partial migrating on the base plane of the SFT. (d ) The mobile Shockley partial interacts with two sessile stai r-rod dislocations, $\mathrm{AB}$ and $\mathrm{AC}$, ge nerates two mobile Shockley

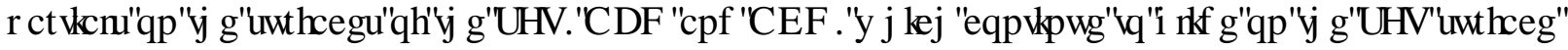
DOGGDGUR WHFRCDSVHRI WH6) 7 
Table 1. A summary of defect sizes and life time and corresponding doses in stages 1 and 2 for nt and cg $\mathrm{Cu}$.

\begin{tabular}{|c|c|c|c|}
\hline \multicolumn{2}{|c|}{} & $\begin{array}{c}\text { Average defect size } \\
\mathbf{( n m )}\end{array}$ & $\begin{array}{c}\text { Life time/accumulated dose } \\
\left(\mathbf{s} / \times \mathbf{1 0}^{-3} \mathbf{d p a}\right)\end{array}$ \\
\hline \multirow{2}{*}{ nt Cu } & stage 1 & 5 & $19 / 8.2$ \\
\cline { 2 - 4 } & stage 2 & 3 & $4 / 7.9$ \\
\hline \multirow{2}{*}{ cg Cu } & stage 1 & 6 & $15 / 6.5$ \\
\cline { 2 - 4 } & stage 2 & 7 & $15 / 29.7$ \\
\hline
\end{tabular}


Figure 1
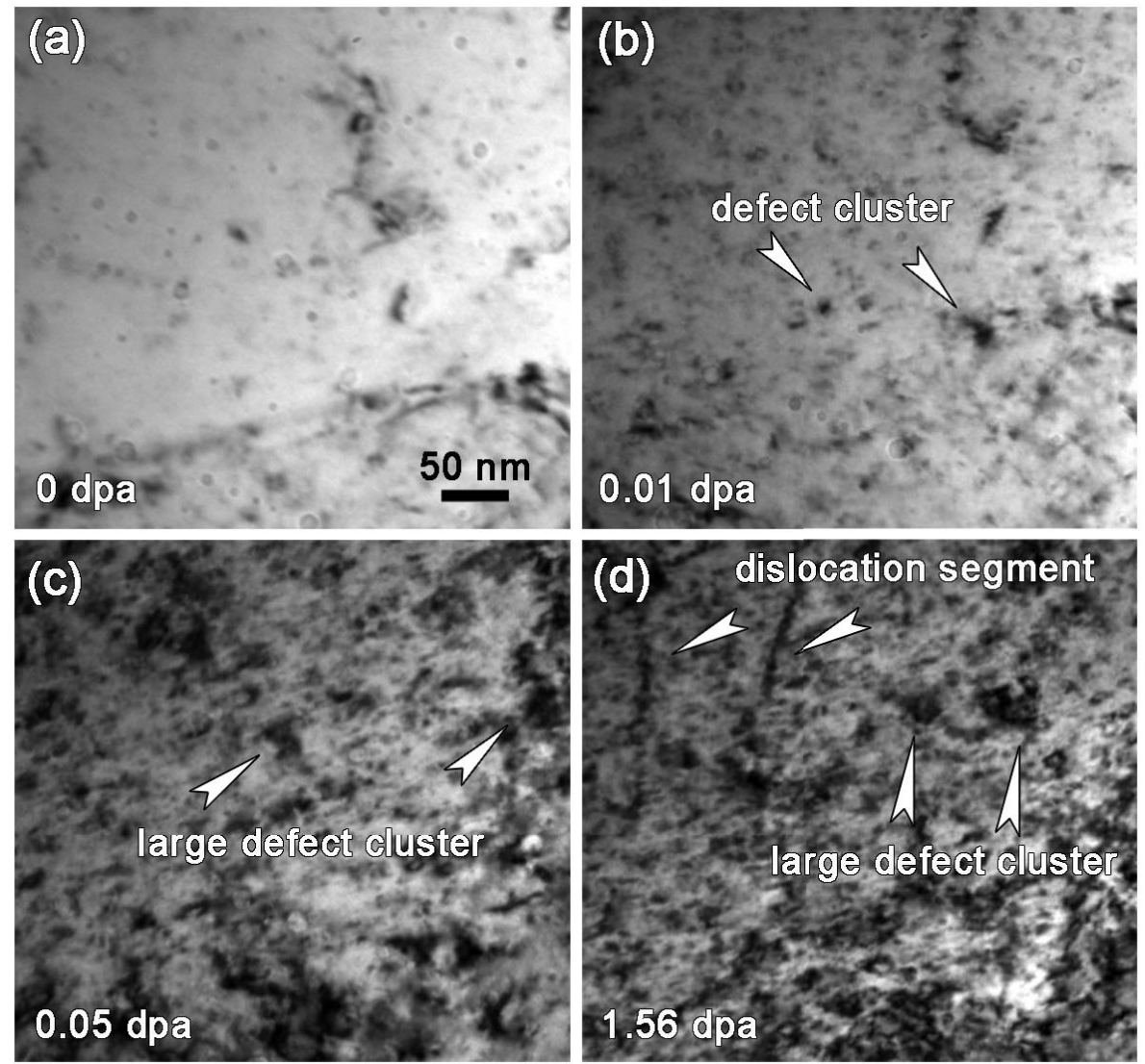
Figure 2
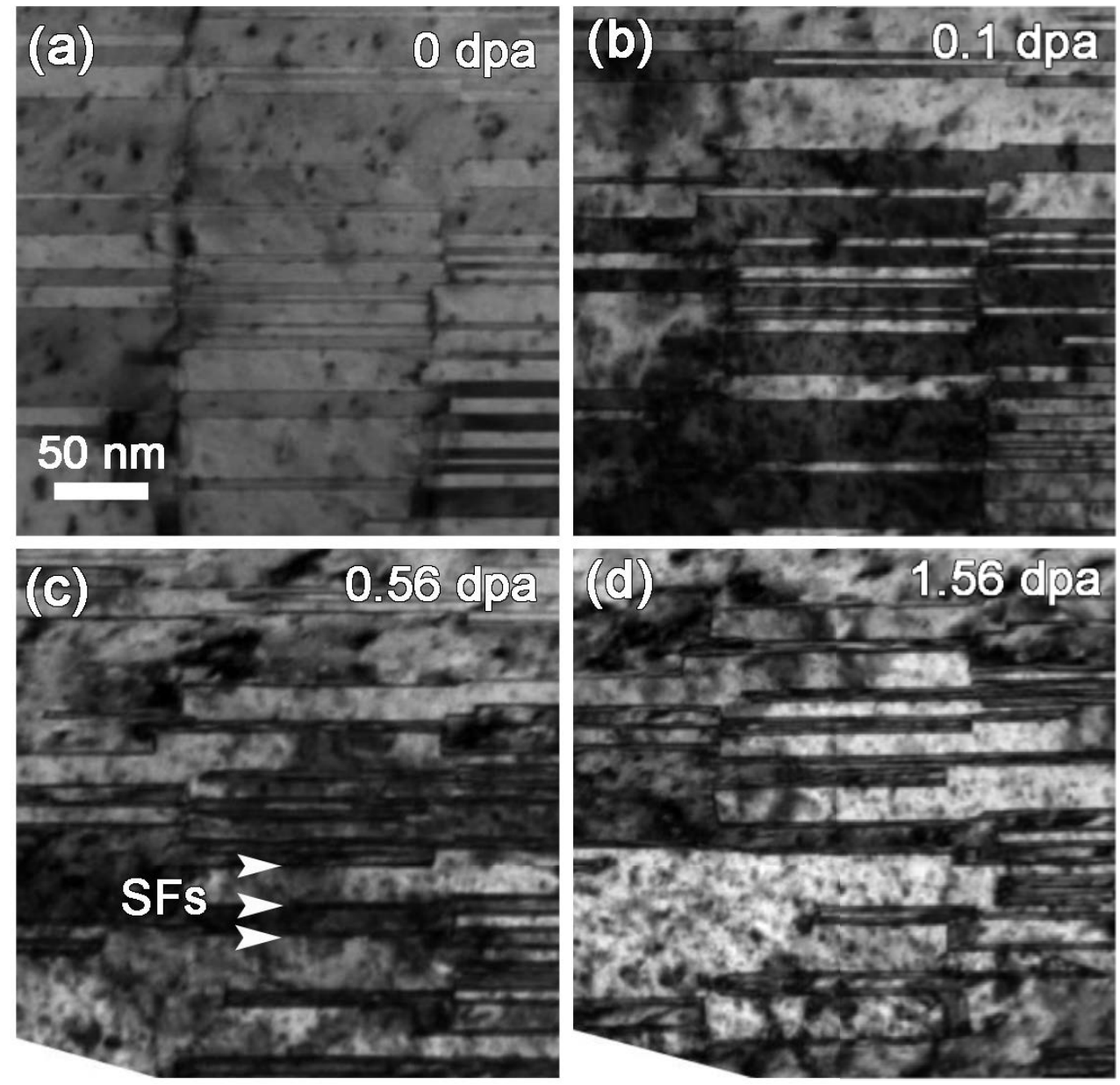
Figure 3

(a) $\mathrm{cg} \mathrm{Cu}$

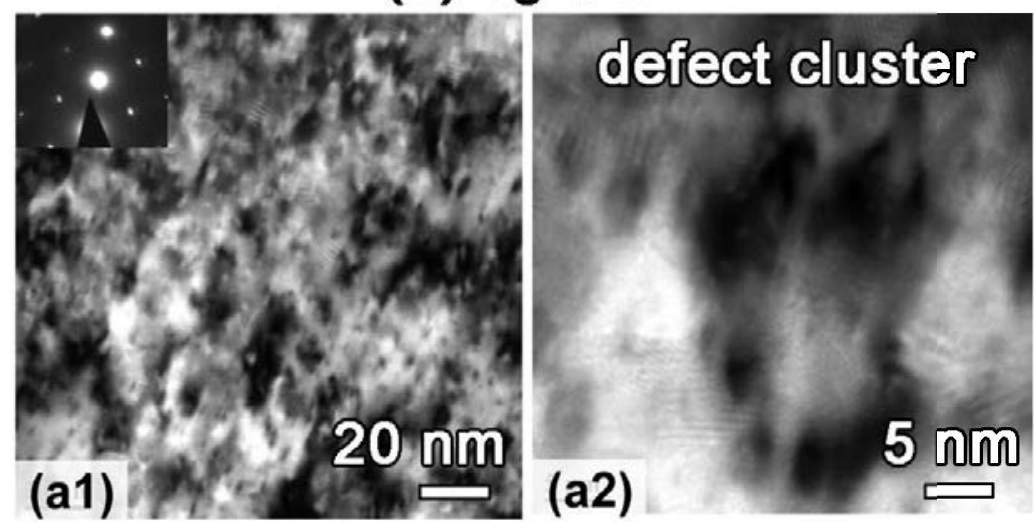

(b) thick twins

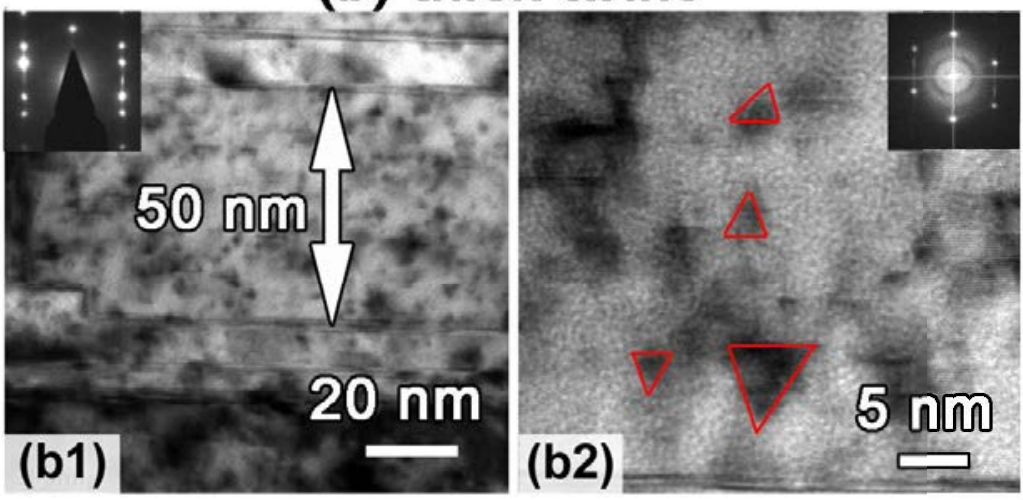

(c) fine twins

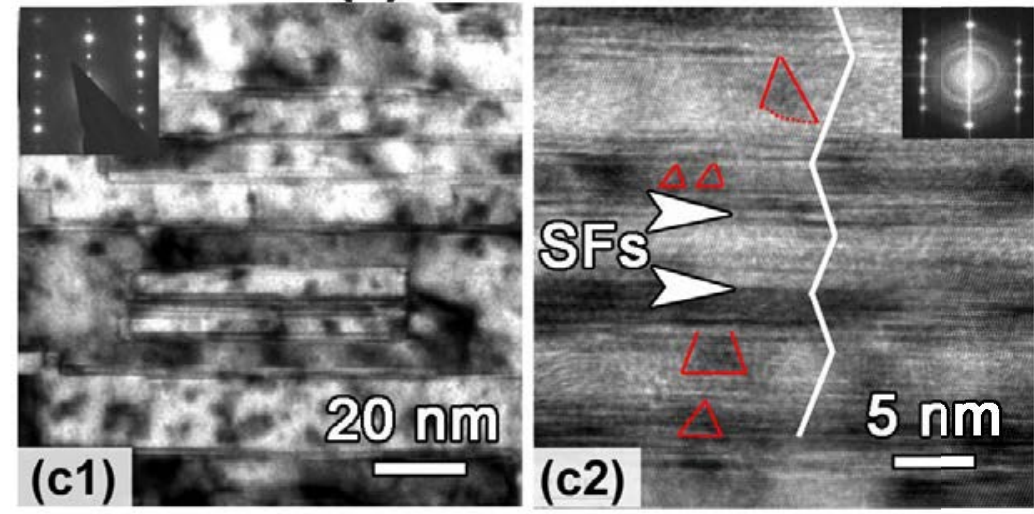


Figure $4 a$

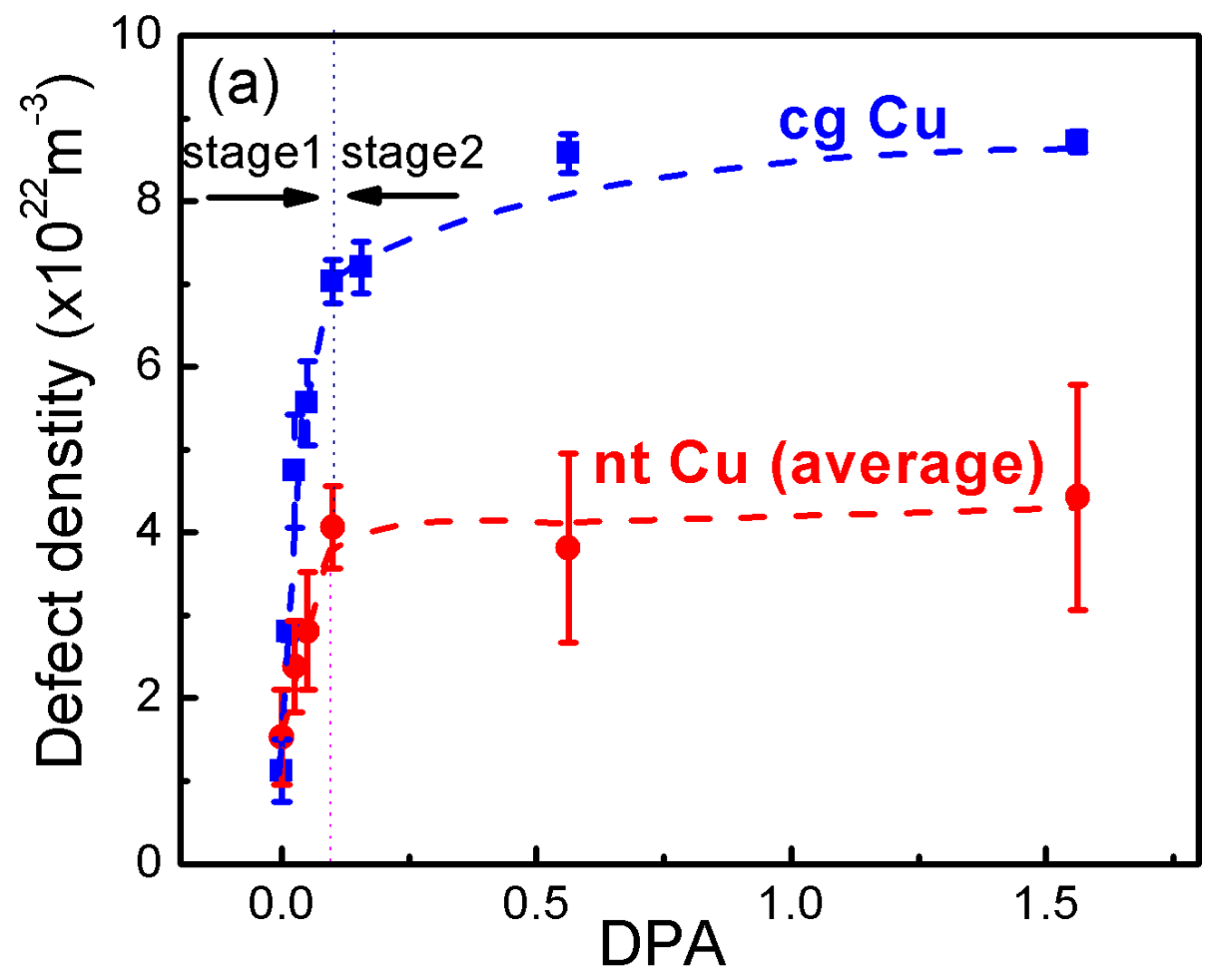


Figure $4 b$

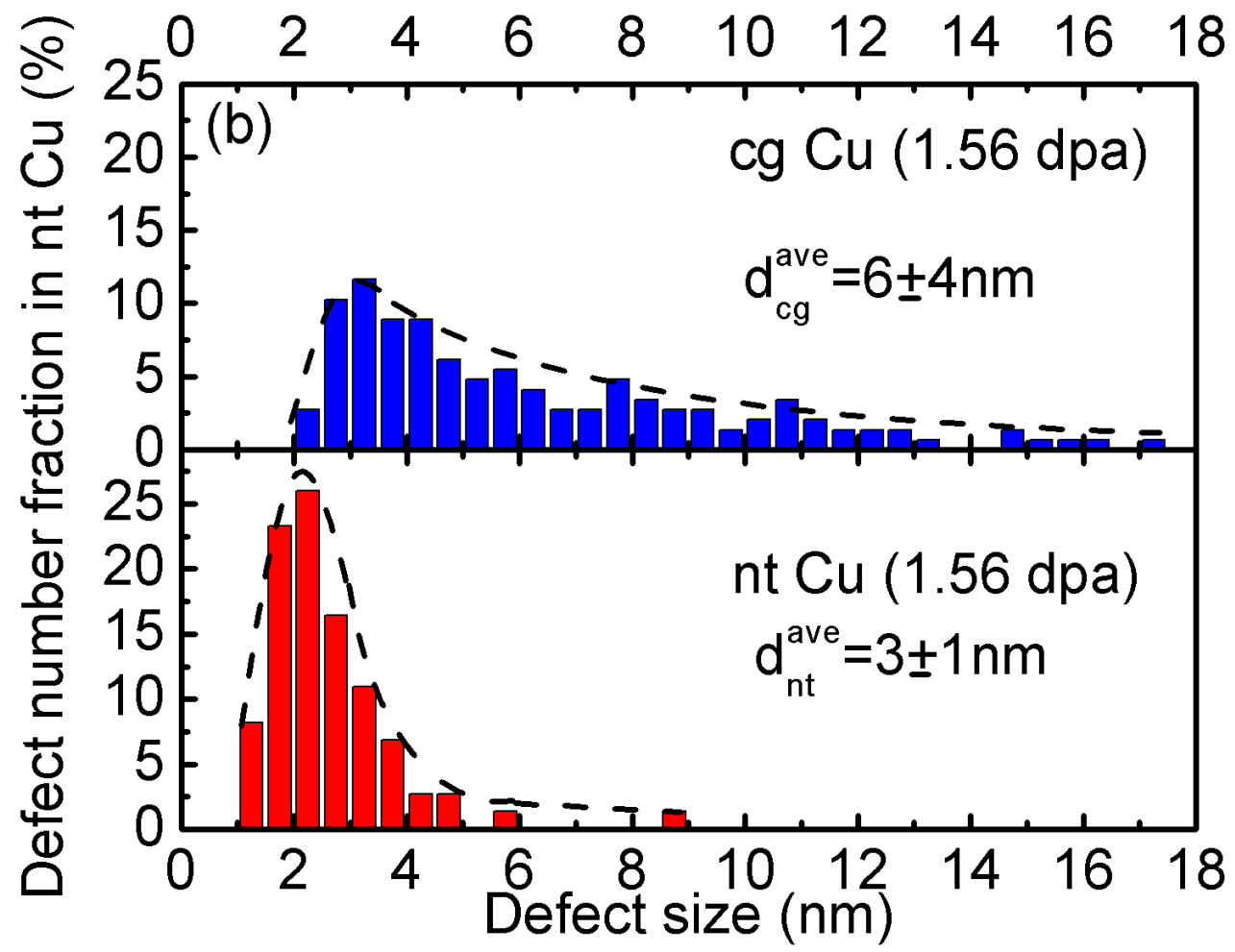


Figure 5
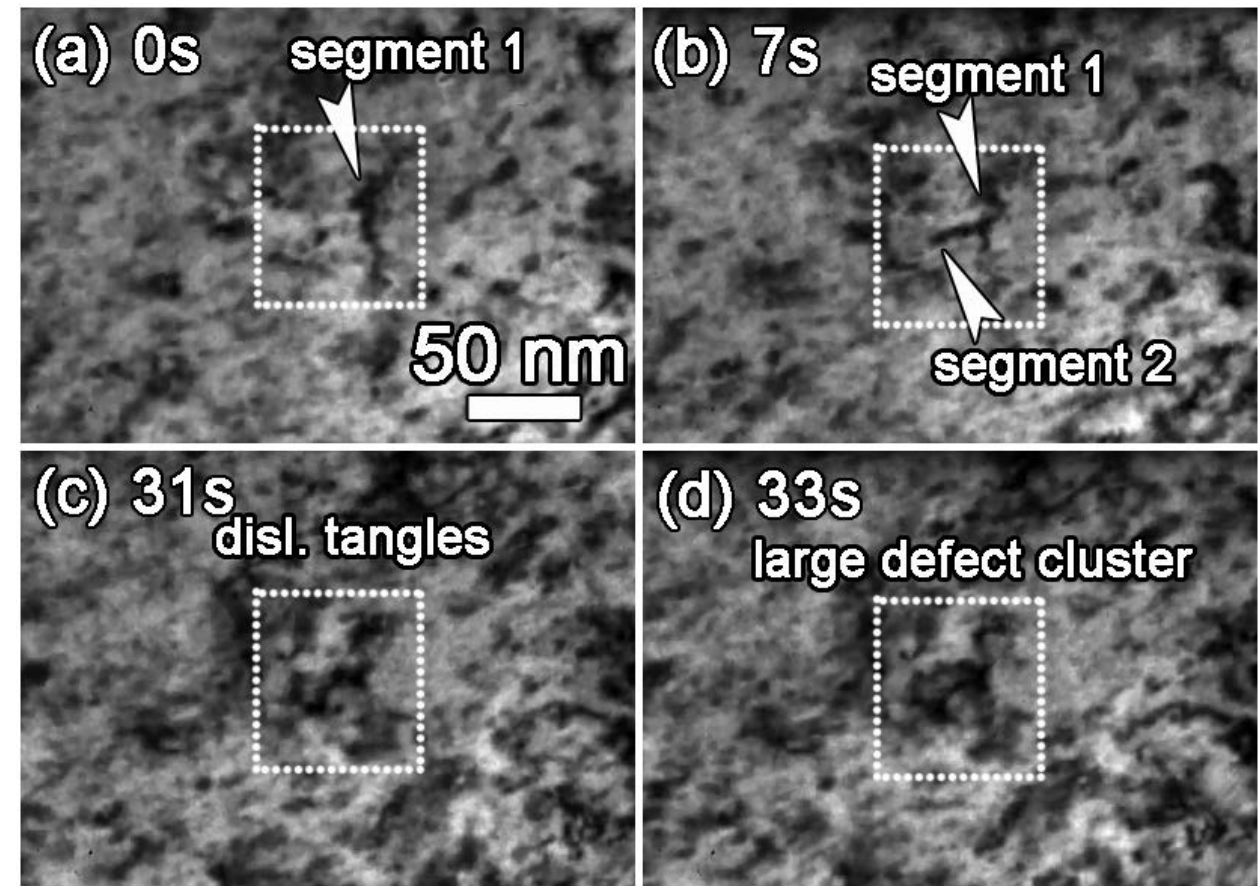
Figure 6

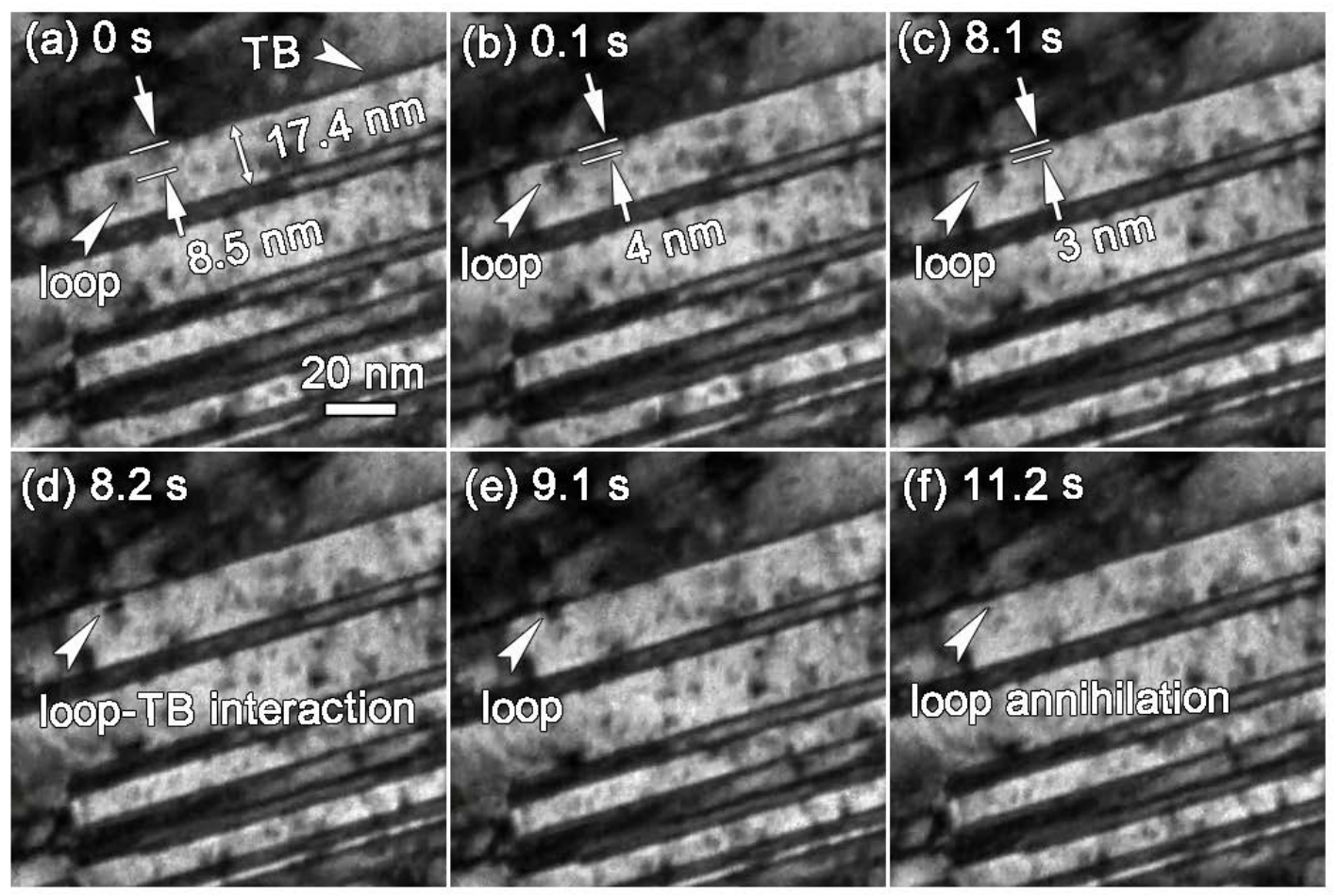


Figure 7

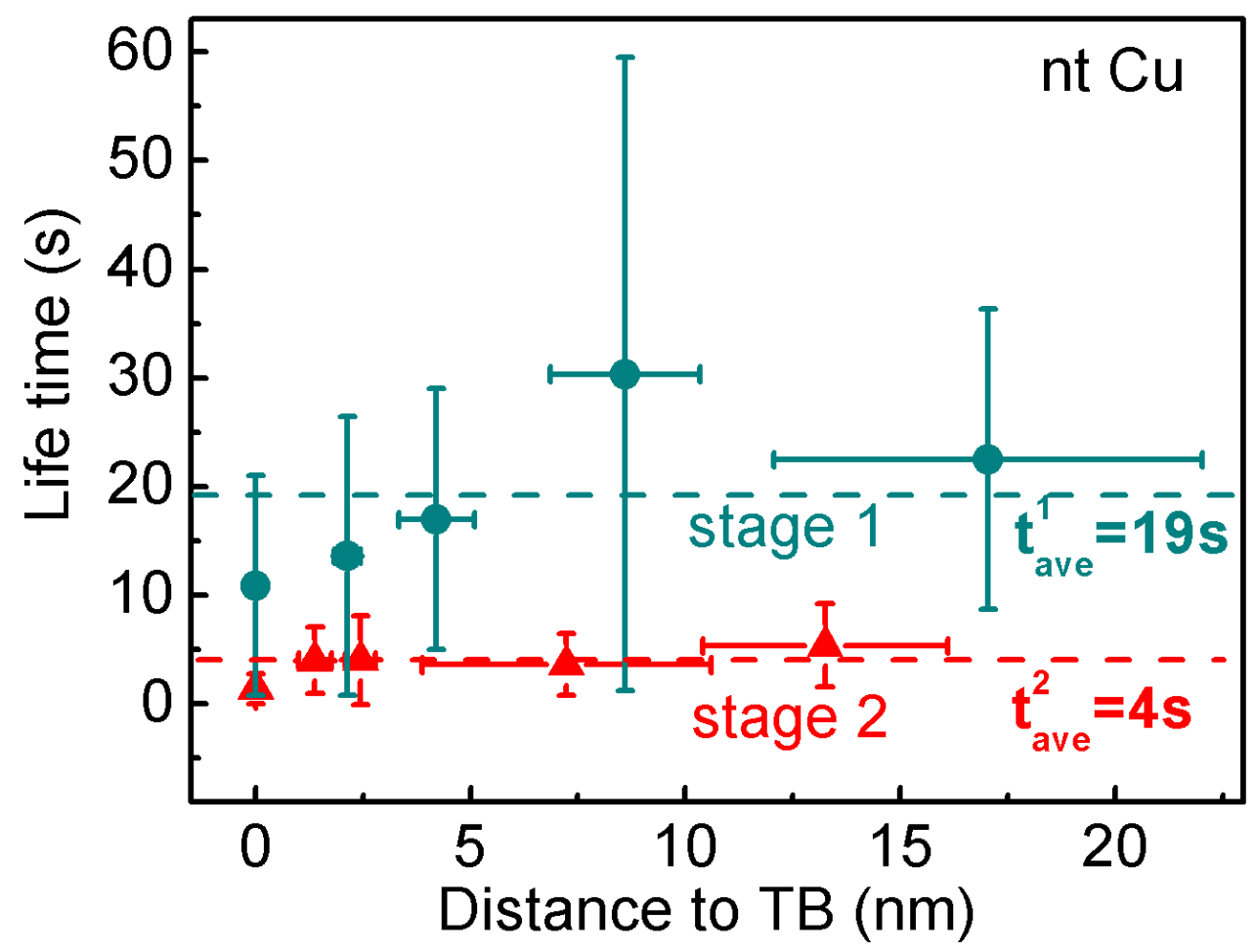


Figure 8

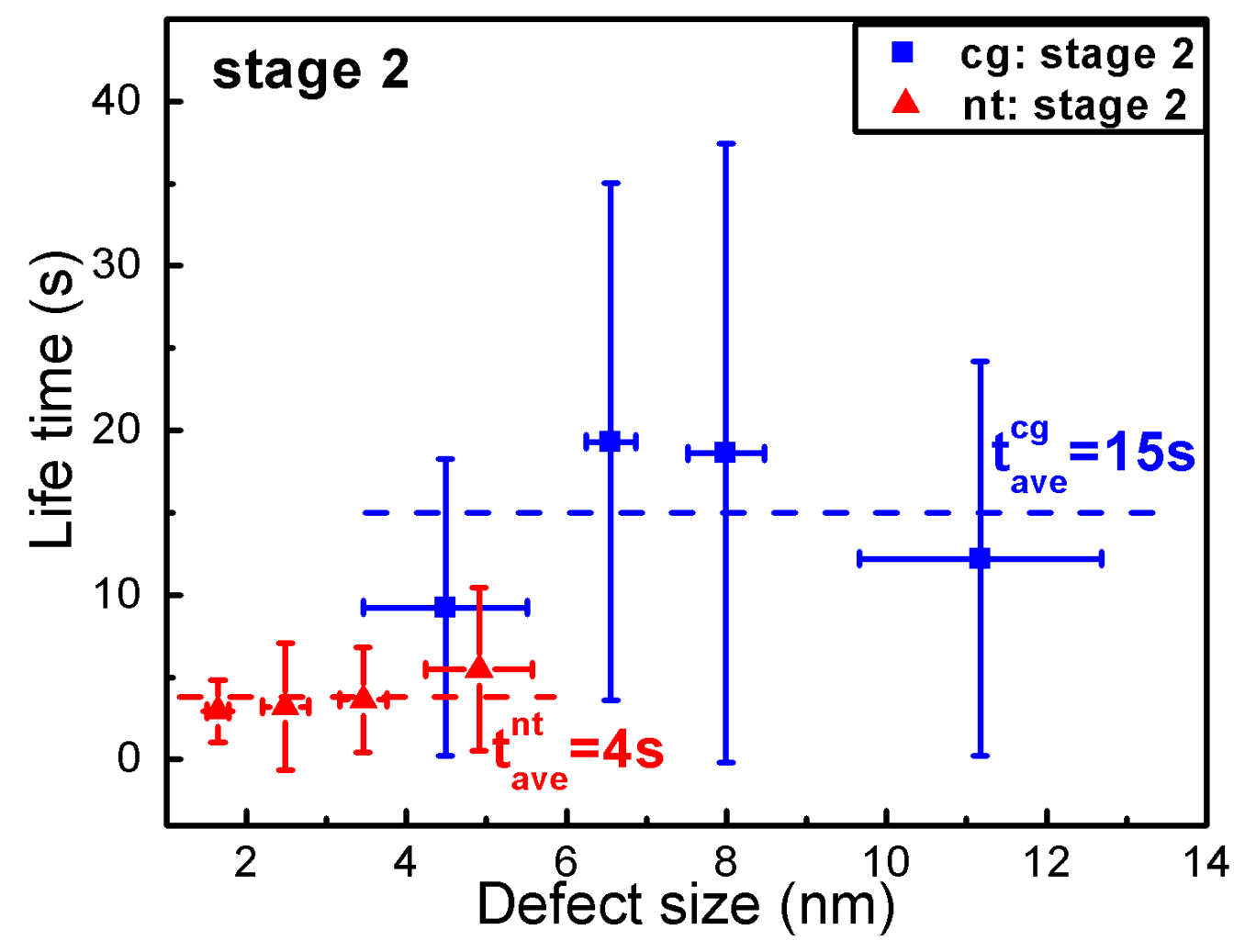


Figure 9

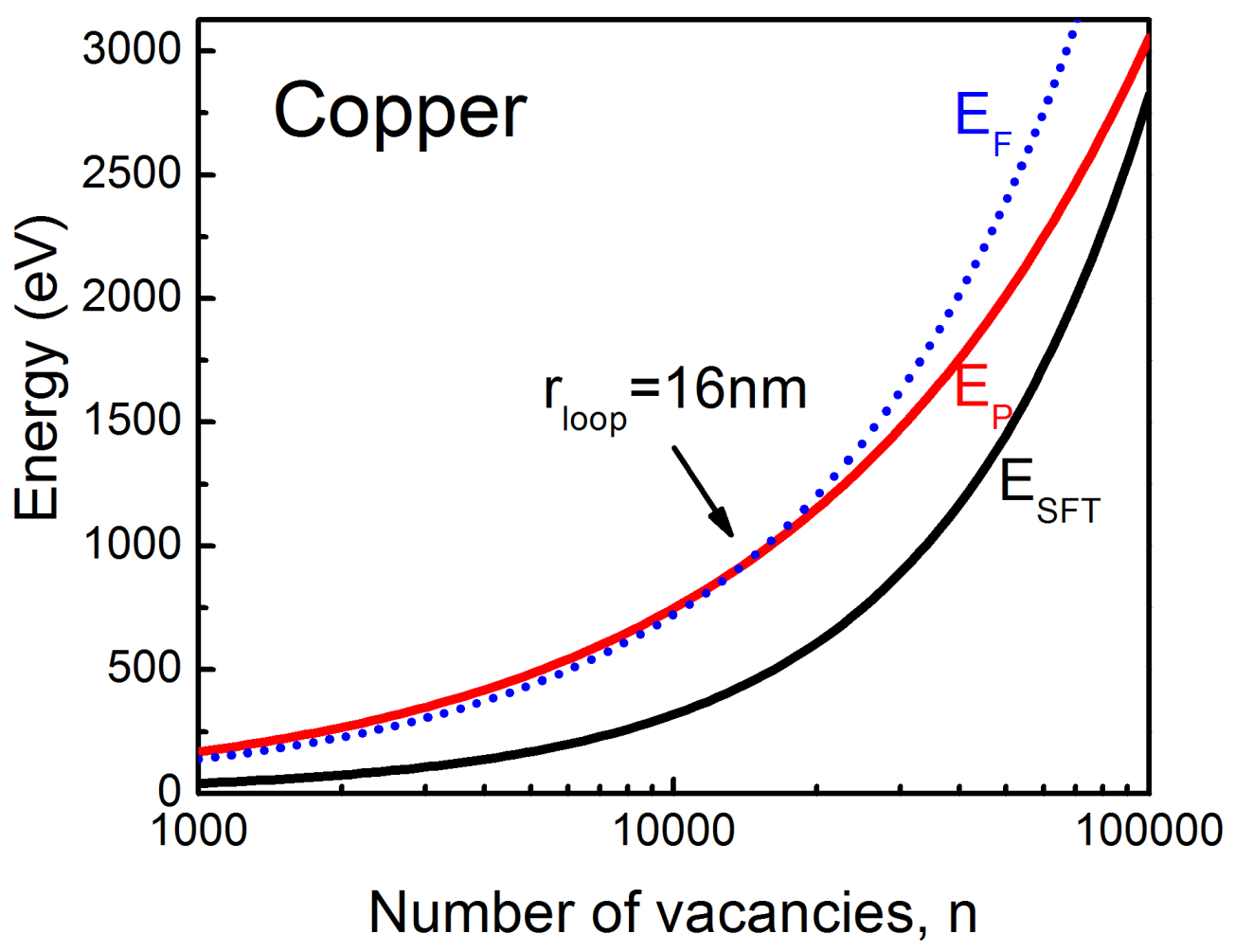


Figure 10

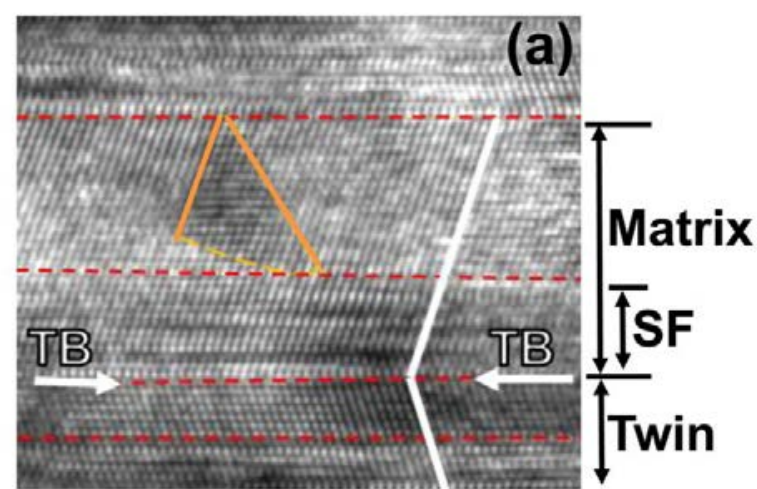

(b)
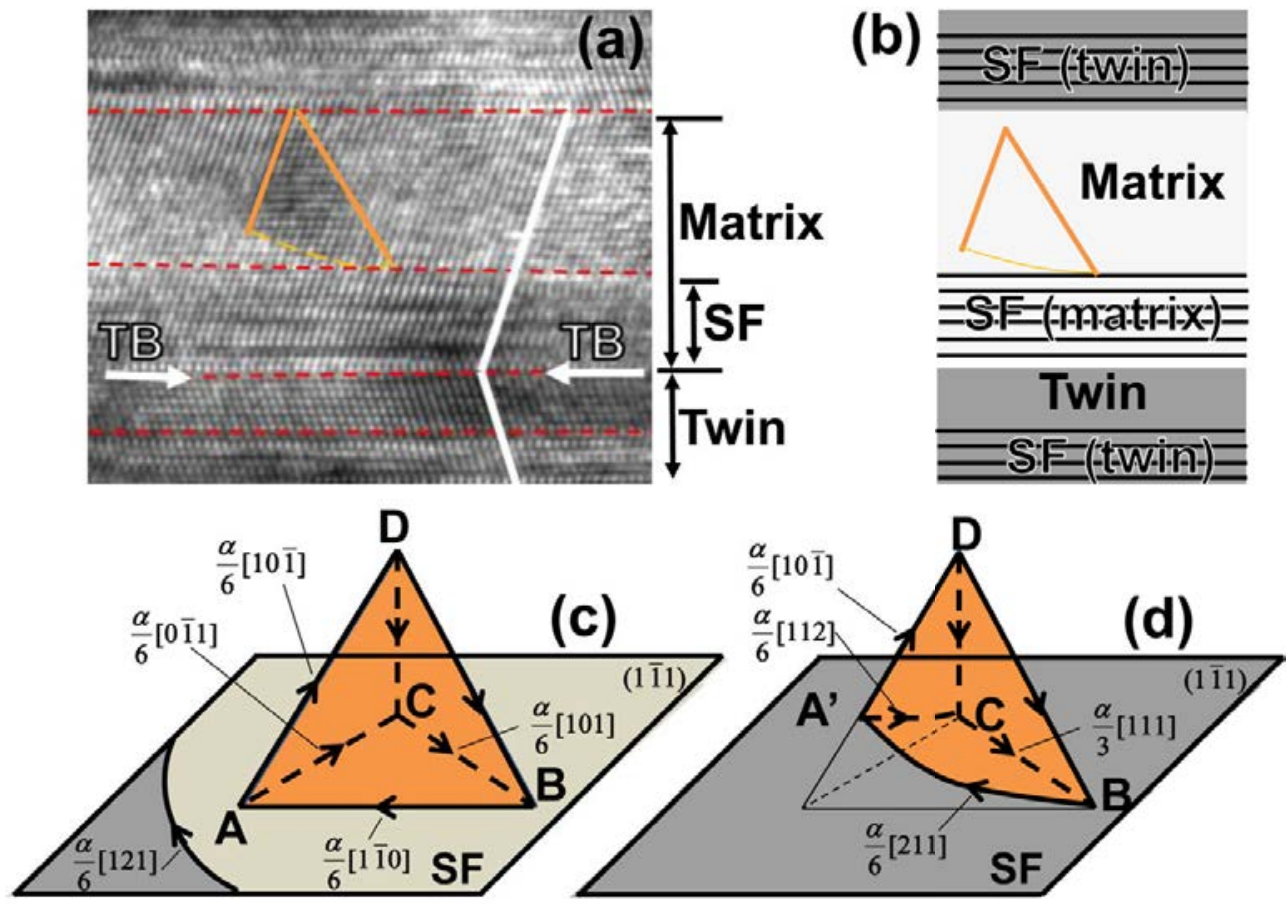
Graphical abstract

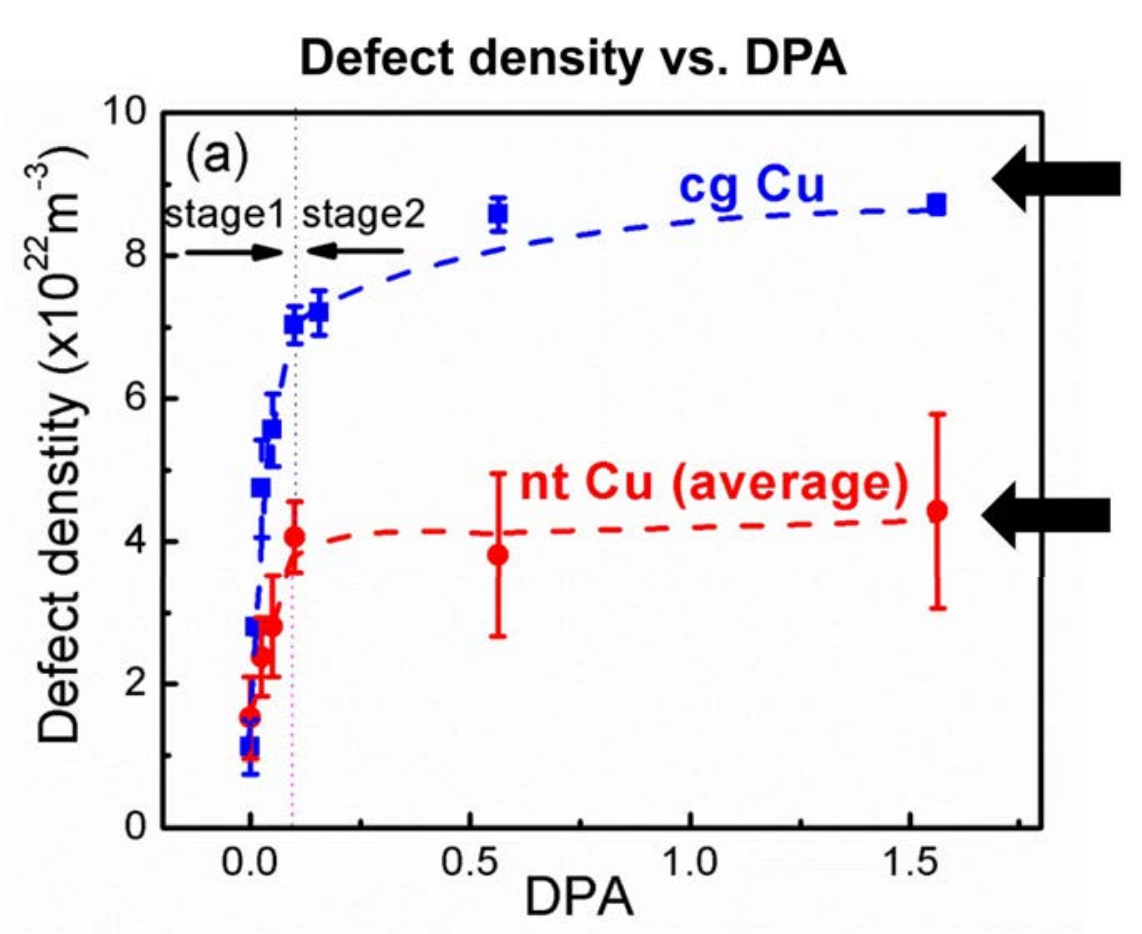

Coarse-grained

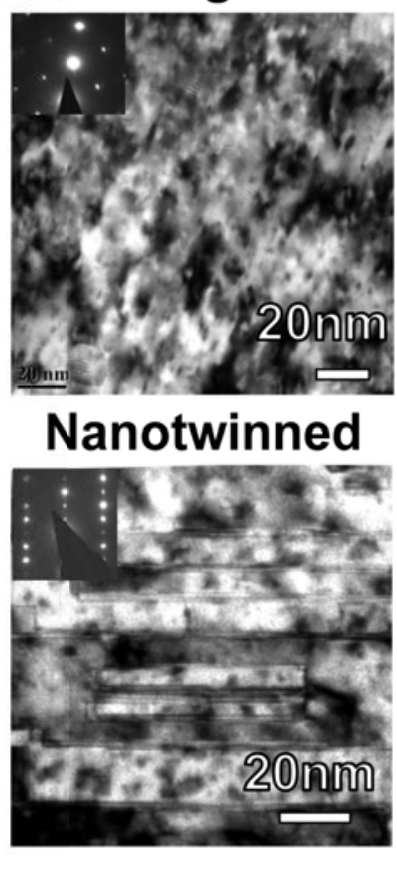

